\title{
Microstructural Evolution and Toughness in the HAZ of Submerged Arc Welded Low Welding Crack Susceptibility Steel
}

\author{
Chunlin $Q I U^{\dagger}$, Liangyun LAN, Dewen ZHAO, Xiuhua GAO and Linxiu DU \\ State Key Laboratory of Rolling and Automation, Northeastern University, Shenyang 110819, China \\ [Manuscript received 7 June 2012, in revised form 4 September 2012] \\ (C) The Chinese Society for Metals and Springer-Verlag Berlin Heidelberg
}

\begin{abstract}
Microstructural characteristics of different sub-regions of heat affected zone (HAZ) of low welding crack susceptibility steel weldment were investigated by using optical microscopy and scanning electron microscopy equipped with electron backscattered diffraction system. And the focus was put on the correlation between microstructural characteristics and HAZ toughness of the weldment. The results reveal that the toughness of fusion line zone (FLZ) specimens is much lower than that of fine grained HAZ (FGHAZ) specimens. The coarse inclusions in the weld metal and the large martensite-austenite constituents in the coarse grained HAZ (CGHAZ) have an obvious negative effect on the crack initiation energy of FLZ. Meanwhile, the coarse granular bainite with large effective grain decreases the crack propagation energy seriously. By contrast, fine crystallographic grains in the FGHAZ play a key role in increasing toughness, especially in improving crack propagation energy.
\end{abstract}

KEY WORDS: Steel; Heat affected zone (HAZ); Submerged arc welding; Effective grain size; Toughness; Microstructure

\section{Introduction}

In recent years, high strength low carbon bainite steels have been widely applied in the field of engineering construction. In order to prevent the deterioration of toughness of welded joint and the occurrence of welding cold cracking, more and more attentions have been attracted to the field about weldability of high strength steel ${ }^{[1,2]}$. The low welding crack susceptibility steel is a kind of easy weldable steel with pre-heating and post-weld heating treatment free. Because of low welding crack susceptibility index value $\left(P_{\mathrm{cm}}\right.$, lower than 0.22$)$, this steel can protect welded joint from cold cracking easily ${ }^{[3]}$. However, the toughness of heat affected zone (HAZ) usually deteriorates seriously because of two main reasons as follows: (1) the sub-region near to the fusion line is subjected to high peak temperature during welding, which results in the occurrence of the austenite grain abnormal growth; (2) the coarse austenite grains commonly transform into upper bainite within the wide range of cooling rate, accompanied by the formation of

\footnotetext{
† Corresponding author. Assoc. Prof.; Tel: +86 2483686419 ; Fax:+86 24 23906472; E-mail address: qiucl@ral.neu.edu.cn (Chunlin QIU)
}

DOI: $10.1007 / \mathrm{s} 40195-012-0103-7$ martensite-austenite $(\mathrm{M}-\mathrm{A})$ constituents $^{[4-6]}$. Additionally, with increasing amount of microalloys addition and upgrading strength grade, the $P_{\mathrm{cm}}$ value as well as carbon equivalent $\left(C_{\text {eq }}\right)$ becomes larger and larger, which may further deteriorate the steel weldability ${ }^{[7]}$. Therefore, the deterioration of HAZ toughness always becomes a hot issue for metallurgical researchers.

In general, the width of the HAZ is very narrow and the microstructures at different sub-regions in welded joint show a very heterogeneous feature. Notably, it is a limitation that the variation of microstructure in the HAZ is investigated only by optical microscopy (OM) and transmission electron microscopy (TEM). In recent, an automated electron backscattered diffraction (EBSD) system attached in the scanning electron microscopy (SEM) has been developed as an effective technique for characterizing complex phases, especially for microtexture and grain boundary misorientation of the intermediate temperature transformation microstructure ${ }^{[8-11]}$. This information can help to further understand the failure mechanism of the welded joints. According to Gourgues et al. ${ }^{[9]}$ research, the crystallographic grains and/or packets (referred to as crystallographic packets) corresponding to the grains or sets of neighboring 
units sharing the same crystallographic orientation, which can be determined by EBSD, have a close relationship with fracture toughness. Different microstructures at subzones of the welded joint having different crystallographic characteristics must be associated with different mechanical properties. Acicular ferrite formed in the weld metal, for example, has a good combination of strength and toughness. Because the high angle grain boundaries of the acicular ferrite can act as obstacles to cleavage propagation, it is beneficial for forcing the cleavage crack to change the microscopic plane of propagation in order to accommodate the new local propagation direction ${ }^{[10,12]}$.

In the present study, submerged arc welding technique was employed to produce the welded joint of the experimental steel plate. The crystallographic features of different sub-zones of HAZ were investigated by EBSD technique. And the correlation of the microstructural characteristics and HAZ toughness was discussed in order to further understand the micromechanism of low HAZ toughness of high strength welded joint.

\section{Material and Experimental Procedure}

The experimental steel plate with a thickness of $20 \mathrm{~mm}$ was produced by the controlled rolling and accelerated cooling technology, and its chemical composition (wt.\%) are as follows: C 0.053 , Si 0.27, Mn 1.2, $\mathrm{Al}$ 0.02, ( $\mathrm{Cr}+\mathrm{Mo}+\mathrm{Ni})$ 0.42, (Nb+V+Ti) 0.082, $\mathrm{B} 0.0014$ and Fe balance. In order to guarantee excellent welding cold crack resistance, the $P_{\mathrm{cm}}$ value of the chemical composition designed was limited to $0.185 \%$ which was obtained in terms of $P_{\mathrm{cm}}=\mathrm{C}+\frac{\mathrm{Si}}{30}+$ $\frac{\mathrm{Mn}+\mathrm{Cu}+\mathrm{Cr}}{20}+\frac{\mathrm{Ni}}{60}+\frac{\mathrm{Mo}}{15}+\frac{\mathrm{V}}{10}+5 \mathrm{~B}^{[3]}$. The main mechanical properties of as-rolled steel are as follows: yield strength is $645 \mathrm{MPa}$, tensile strength is $760 \mathrm{MPa}$ and impact absorbed energy at $-20{ }^{\circ} \mathrm{C}$ is $161 \mathrm{~J}$. The microstructure consists of fine polygonal ferrite, acicular ferrite and granular bainite as shown in Fig. 1. Granular bainite has a large morphological grain size and some prior austenite grain boundaries are retained due to acceleration cooling process promoting bainite transformation.

The base plate with size of $20 \mathrm{~mm}$ (thickness) $\times$ $100 \mathrm{~mm}$ (width) $\times 400 \mathrm{~mm}$ (length) was cut along the longitudinal dirction of hot rolled steel. A Vtype welded joint design was adopted and four passes welding procedure was conducted to generate a relative large HAZ section. The main welding parameters are represented in Table 1 . The low-alloy steel electrode (H08MnMoA) and fluxes (SJ101) were used for submerged arc welding. But it is obvious that the weld metal strength undermatched with the base metal strength. According to ISO 9016 standard ${ }^{[13]}$,

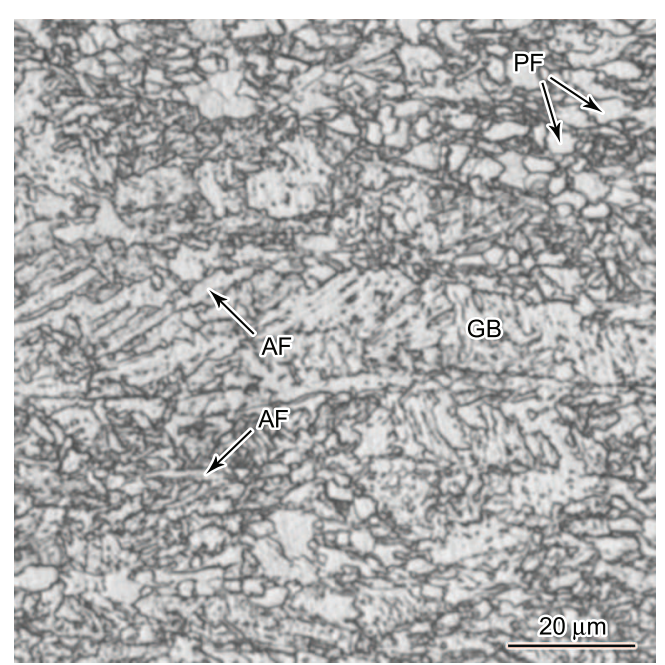

Fig. 1 Optical image showing the base metal microstructure (PF: polygonal ferrite, GB: granular ferrite, AF: acicular ferrite)

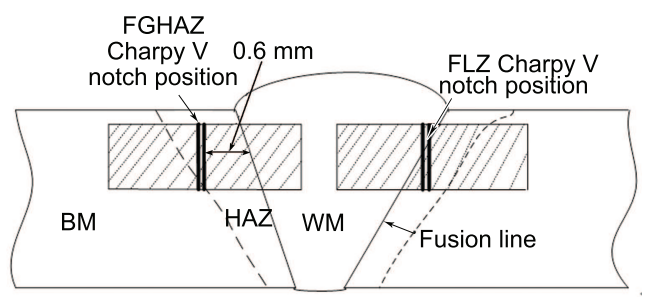

Fig. 2 Schematic diagram of Charpy $\mathrm{V}$ notch position (FLZ Charpy $\mathrm{V}$ notch position across the fusion line, while FGHAZ Charpy V notch position about $0.6 \mathrm{~mm}$ away from the fusion line, WM: weld metal, BM: base metal)

Charpy V notch of impact specimens with the standard size is positioned at a certain location in the welded joint to investigate the fusion line zone (FLZ) and fine grained HAZ (FGHAZ) toughness, as shown schematically in Fig. 2. In order to fix the position of Charpy $\mathrm{V}$ notch clearly, all impact specimens were macro-etched firstly with $3 \%$ nital. The Charpy $\mathrm{V}$ notch position of FGHAZ specimens was fixed at about $0.6 \mathrm{~mm}$ away from the fusion line in order to exclude the effect of coarse microstructure on the FGHAZ toughness. In fact, it is inevitable that the toughness of FLZ specimens certainly contains two neighbouring sub-zones toughness of weld metal (WM) and coarse grained HAZ (CGHAZ); while the FGHAZ toughness consists of other three sub-zones toughness of FGHAZ, intercritical HAZ (ICHAZ) and a part of tempered zone according to Fig. 2. To guarantee the effectiveness of the impact specimens, the cross section of each specimen was etched and observed after impact testing.

An instrumented drop weight impact tester was

Table 1 Average value of main welding parameters of four-pass submerged arc welding process

\begin{tabular}{ccccc}
\hline Current $/ \mathrm{A}$ & Voltage $/ \mathrm{V}$ & Welding speed $/(\mathrm{mm} / \mathrm{min})$ & Inter-pass temperature $/{ }^{\circ} \mathrm{C}$ & Heat input $/(\mathrm{kJ} / \mathrm{cm})$ \\
\hline 600 & $28-35$ & 400 & $180-200$ & $25.0-31.5$ \\
\hline
\end{tabular}




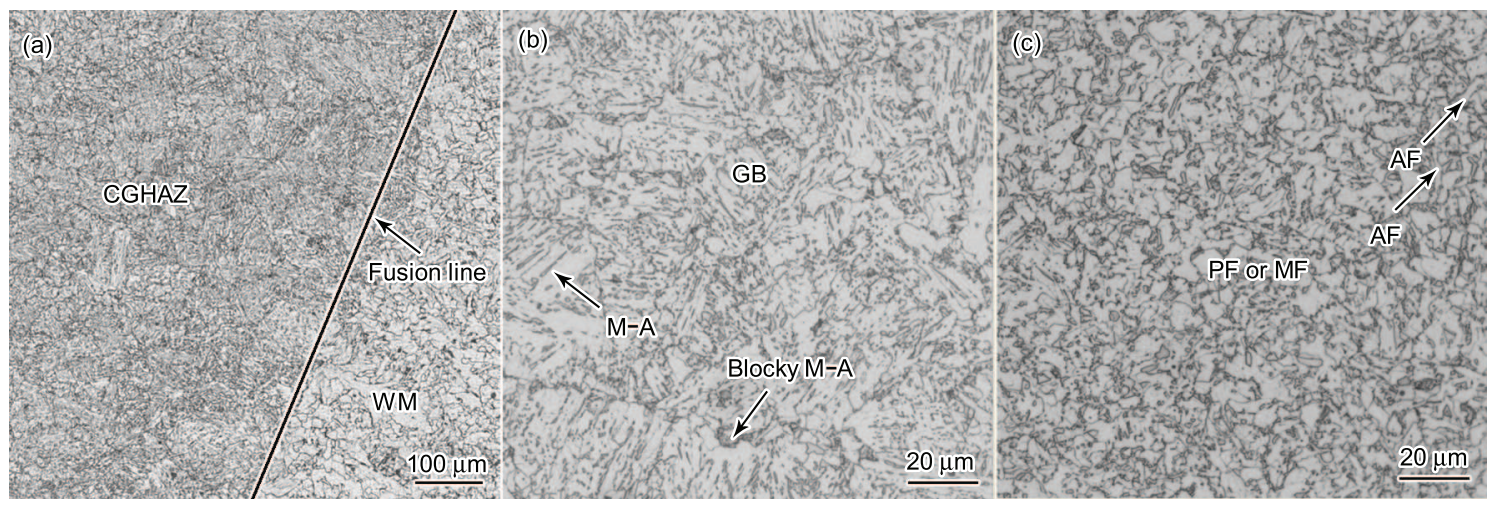

Fig. 3 Microstructures of FLZ (a), CGHAZ (b) and FGHAZ (c) in HAZ (WM: weld metal, GB: granular bainite, M-A: martensite-austenite constituent, PF: polygonal ferrite, MF: massive ferrite, AF: acicular ferrite)

employed to examine impact toughness and record the impact force and impact absorbed energy curves. The impact testing was carried out at $-20^{\circ} \mathrm{C}$ and each region was tested at least five times. The metallographic specimen was cut from the welded plate on transverse section with respect to the welding direction. The polished specimen was etched with $3 \%$ nital for optical microscope observation. The fracture surfaces of the impact specimens were observed by using SEM (FEIQuanta 600). The metallographic specimen was repolished using diamond paste and electrochemically polished in a solution containing 80 vol.\% ethanol, 12 vol.\% distilled water and 8 vol.\% perchloric acid, operating at $28 \mathrm{~V}$ and $-25^{\circ} \mathrm{C}$. Crystallographic feature analyses of different sub-zones microstructures were conducted on the SEM equipped with an EBSD system.

\section{Results and Discussion}

\subsection{Microstructural characteristics}

Fig. 3 shows the microstructures at different subzones of the welded joint. Because the strength of weld metal is lower than that of the base metal, the microstructures are obvious different at two sides of the fusion line. The weld metal mainly contains ferrite side plate and polygonal ferrite as shown in Fig. 3(a). By contrast, the CGHAZ neighboring the fusion line has predominantly granular bainite with large prior austenite grain size as shown in Fig. 3(b). Meanwhile, quite a number of $\mathrm{M}-\mathrm{A}$ constituents can be observed along the grain boundaries and inside the grains. The M-A constituents have three different morphologies: large blocky shape, stringer shape and small dot shape. The maximum aspect ratio (length/width) of $\mathrm{M}-\mathrm{A}$ constituent observed can reach 25 , and the maximum length of blocky $\mathrm{M}-\mathrm{A}$ constituent can reach about $5 \mu \mathrm{m}$. These $\mathrm{M}-\mathrm{A}$ constituents with large size have a significant negative effect on the toughness because they can provide the nucleation sites for cleavage microcrack proposed by Davis et al. ${ }^{[14]}$. The microstructure of FGHAZ consists of polygonal ferrite (or massive ferrite), acicular ferrite and little granular bainite with a very small morphology size as shown in Fig. 3(c).

\subsection{Impact toughness}

The typical curves of the impact force and impact absorbed energy as a function of the loading time during impact testing can be monitored by using an instrumented drop weight impact tester, as shown in Fig. 4. The crack initiation and crack propagation energies can be obtained directly from these curves according to the peak force. The impact curve shows the whole process of fracture and was described in detail in Ref. [15]. The average values of impact toughness are given in Table 2 . The crack propagation energy of the FLZ specimen is very low because the impact force decreases immediately and quickly after it reaches the peak value, as shown in Fig. 4(a). By contrast, the impact curve of FGHAZ specimen performs a good ability to hinder the crack propagation, as shown in Fig. 4(b). Besides, the crack initiation energy of FLZ is lower than that of FGHAZ because of lower peak force value for the FLZ specimens.

The SEM micrographs in Fig. 5 show the morphologies of the fracture surface of the impact specimens. As mentioned above, the FLZ specimens actually contain two sub-zones of WM and CGHAZ. Therefore, the morphology of the fracture surface exhibits two kinds of different features as shown in Fig. 5(a) and (b). The WM zone has a relatively large unit cleavage facet with quite a number of coarse inclusions distributing on the cleavage surface (Fig. 5(a)). These inclusions arrowed in Fig. 5(a) can act as the triggers for the initiation of cleavage

Table 2 Results of Charpy test at $-20^{\circ} \mathrm{C}$

\begin{tabular}{ccccc}
\hline Specimen & $F_{\mathrm{p}} / \mathrm{kN}$ & $E_{\mathrm{i}} / \mathrm{J}$ & $E_{\mathrm{p}} / \mathrm{J}$ & $E_{\mathrm{t}} / \mathrm{J}$ \\
\hline FLZ & 20.8 & 27.2 & 18.4 & 45.6 \\
FGHAZ & 24.3 & 52.4 & 83.9 & 136.3 \\
\hline
\end{tabular}

Notes: $F_{\mathrm{p}}$ : Peak force, $E_{\mathrm{i}}$ : crack initiation energy, $E_{\mathrm{p}}$ : crack propagation energy, $E_{\mathrm{t}}$ : total absorbed energy 

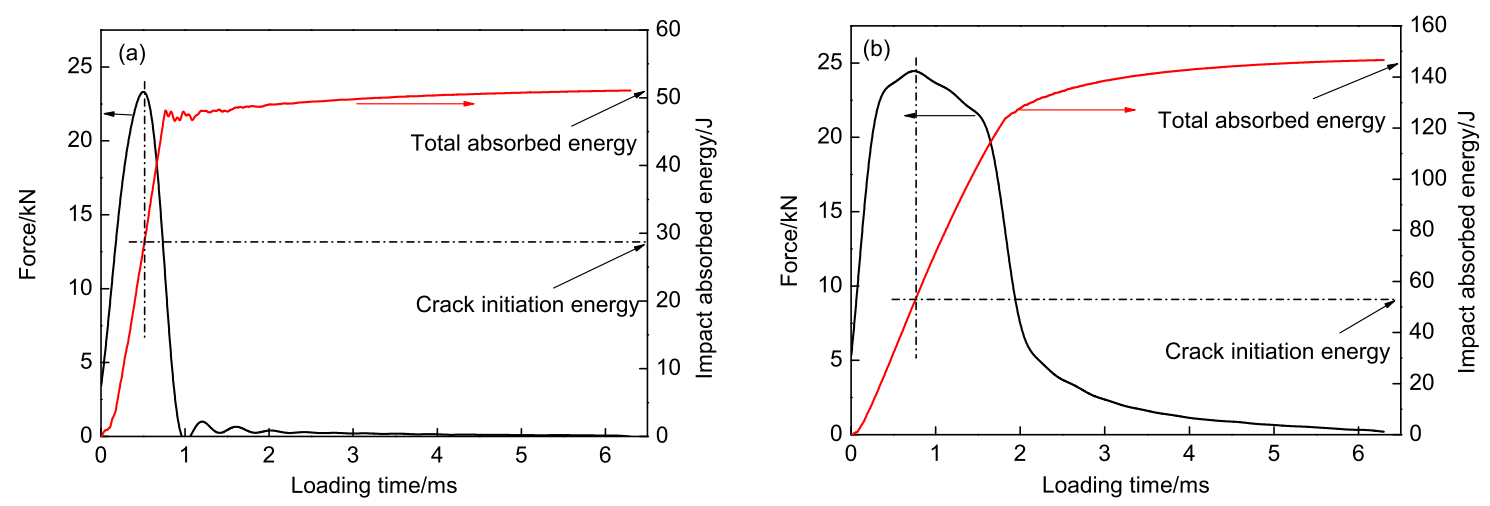

Fig. 4 The typical curves of impact force and impact absorbed energy vs. loading time of FLZ (a) and FGHAZ (b) impact specimens in the HAZ

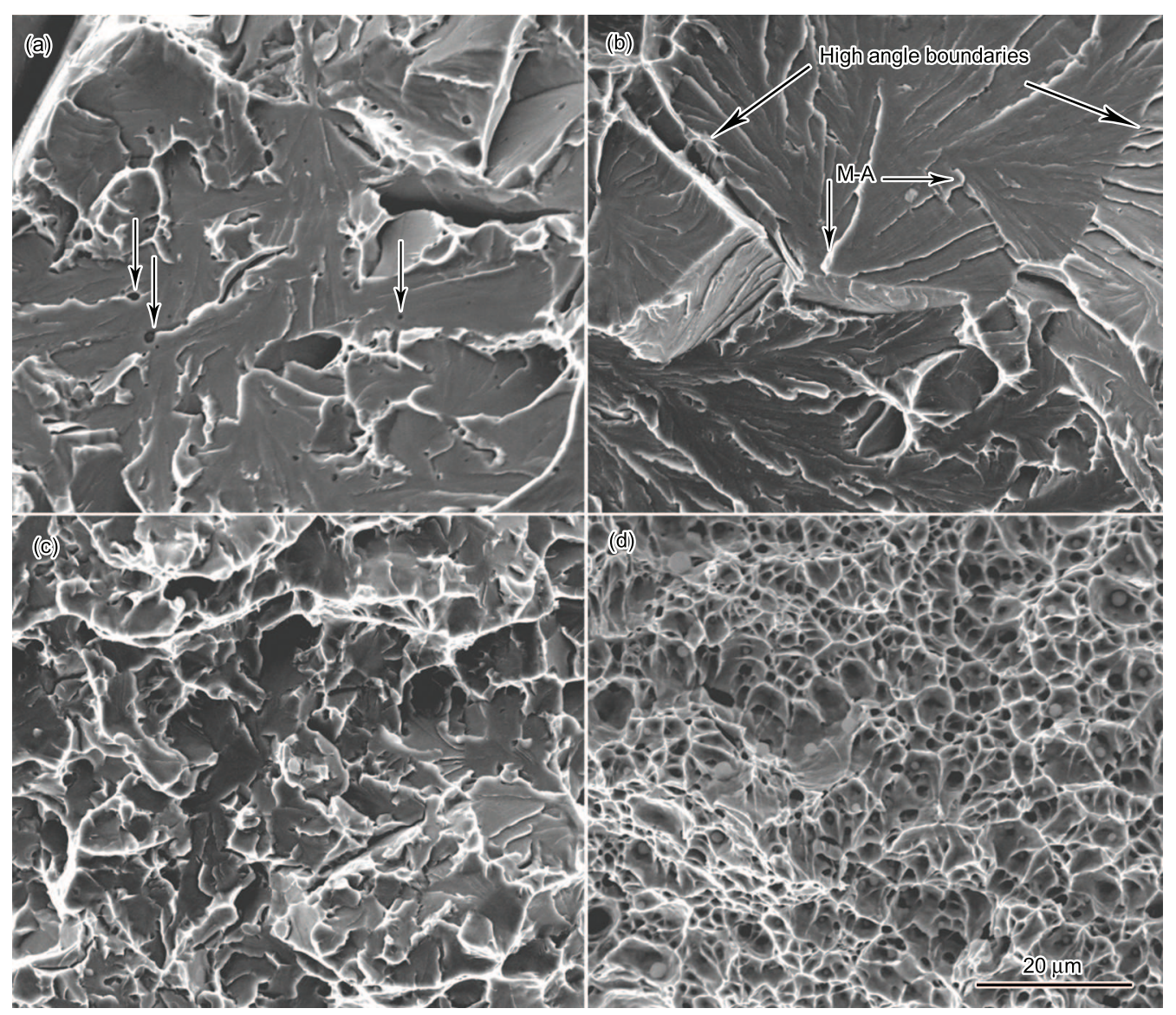

Fig. 5 Fracture morphology features of the FLZ (a, b) and FGHAZ (c, d) impact specimens, tested at $-20^{\circ} \mathrm{C}$

$\operatorname{crack}^{[12]}$. The fracture morphology of CGHAZ performs completely cleavage fracture feature with coarse unit cleavage facet. This unit cleavage facet always initiates on the $\mathrm{M}-\mathrm{A}$ constituents attached to the grain boundaries and stops or deflects at the high angle grain boundaries, as shown in Fig. 5(b). Obviously, the coarse inclusions and $\mathrm{M}-\mathrm{A}$ constituents in FLZ specimens decrease the crack initiation energy seriously. On the contrary, the fracture morphology of FGHAZ specimens reveals a mixture of quasi-cleavage fracture and ductile fracture as shown in Fig. 5(c) and $(\mathrm{d})$. The quasi-cleavage fracture region has very small unit cleavage facet compared with the FLZ specimens. The ductile fracture region has many small dimples which may play an important role in improving the FGHAZ toughness. According to cleavage fracture mechanism ${ }^{[12,15-17]}$, the small unit cleavage facet for FGHAZ specimen can reflect its good ability to hinder crack propagation because fine unit cleavage facet means that the crack propagation direction may change, which can deplete quite a number of crack propagation energy. The unit cleavage facet and impact toughness are well known to be closely related to crystallographic orientation feature of the microstructure because only high misorientation grain boundaries (the threshold value of high misorientation angle is usually defined at $15^{\circ}$ ) can effectively deflect and / or arrest the microcrack propagation ${ }^{[9-12,17,18]}$. Thus, 
the effect of crystallographic features of different subzones in welded joint on the toughness should be analyzed by using EBSD technique and discussed in detail below.

\subsection{EBSD analyses}

Due to quite complex intermediate transformation microstructures formed in the welded joint, it is hard to obtain accurate information for explaining the mechanical properties at each sub-zone only based on optical micrograph. Therefore, EBSD technique was employed to analyze the crystallographic orientation of microstructure at each sub-zone. The orientation color map and image quality map with high misorientation grain boundaries distribution accounting for the FLZ crystallographic features are shown in Fig. 6(a) and (b), respectively. The black line with an arrow represents the fusion line, and each color represents one crystallographic orientation, as shown in Fig. 6(a). It can be seen that granular bainite in the CGHAZ has the large crystallographic size feature, while quasi-polygonal ferrite grains in the WM zone have relatively small crystallographic domain. This information can be also testified by the grain boundaries misorientation distribution in Fig. 6(b), where the high misorientation boundaries (more than $15^{\circ}$ ) were pictured with blue lines. Generally, the high-angle grain boundaries can be considered as the effective grain boundaries to hinder crack propagation in the matrix ${ }^{[10]}$. The maximum effective grain size of the granular bainite observed can reach almost $50 \mu \mathrm{m}$, which indicates that the crack can propagate in a straight line at this region. The average effective grain size at the CGHAZ obtained is about $15.7 \mu \mathrm{m}$. This value reasonably explains the coarse unit cleavage facet size in the fracture morphology of the impact specimens, because the unit cleavage facet size is related to and appears to be somewhat larger than the effective grain size ${ }^{[10]}$. Additionally, as shown in Fig. 6(c), the point to point misorientations change along the lines 1 and 2 signified in Fig. 6(b) were examined inside the coarse granular bainite grain. It is revealed that the maximum misorientation angles of both lines were lower than $10^{\circ}$ and these point to point misorientation curves exhibit a fluctuant variation, which indicates the existence of high density of sub-boundaries inside the granular bainite grain. These sub-boundaries, which mainly result from medium-temperature phase change and welding


Fig. 6 EBSD results showing crystallographic features of the FLZ: (a) orientation color map; (b) image quality map with high misorientation grain boundary distribution; (c) misorientations variation along the lines 1 and 2 signified in Fig. 6(b); (d) $\{100\}$ pole figure 

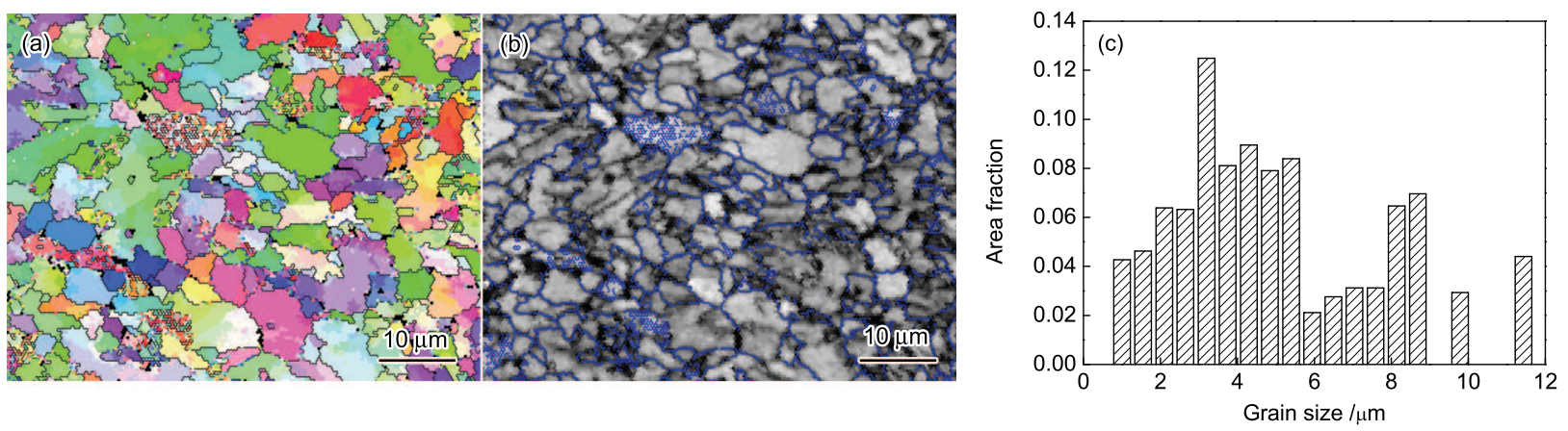

Fig. 7 EBSD results showing crystallographic features of the FGHAZ: (a) orientation color map; (b)image quality map with high misorientation grain boundary; (c) grain size distribution

residue inside stress, can enhance the strength of FLZ, but, to a certain extent, decrease the toughness ${ }^{[18]}$. Fig. 6(d) shows the $\{100\}$ pole figure of the FLZ and the strong orientation of coarse granular bainite at the CGHAZ are marked with cycles. That is to say, the CGHAZ has very strong texture. The weld metal attached to the CGHAZ usually holds the consistent orientation at the fusion boundary, which can be inferred that the CGHAZ in the vicinity of fusion line provides ideal heterogeneous nucleation sites for weld metal $^{[19]}$.

The process of brittle cleavage fracture in the welded joint can be divided into several stages ${ }^{[10,17]}$ : the first of them is the nucleation of a microcrack in a brittle element which, for the CGHAZ, is the hard phase such as $\mathrm{M}-\mathrm{A}$ constituent and the microcrack immediately reaches the boundary of $\mathrm{M}$ A constituents-matrix. The second stage is that the microcrack propagates into the surrounding matrix across the $\mathrm{M}-\mathrm{A}$ constituent-matrix interface and reaches the first matrix-matrix interface, i.e. the high angle grain boundary, finally, the progression of the microcrack through the matrix leads to final failure. It is generally accepted that the second stage takes place mainly through $\{100\}$ cleavage planes ${ }^{[10,20,21]}$. Therefore, the $\{100\}$ plane is the cleavage plane of bcc iron crystal, a high density of $\{100\}$ planes parallel to microcrack propagation direction should lead to a lower fracture energy. As shown in Fig. 6d, the high density of poles at the FLZ parallel to the transverse direction of the impact specimen implies a polycrystallography, which is conducive to cleavage crack propagation $^{[21]}$. Therefore, the FLZ has very low crack propagation energy (see Table 2).

The orientation color map, image quality map with high angle grain boundary distribution as well as crystallographic grain size distribution of the FGHAZ are shown in Fig. 7. Each small polygonal ferrite grain has an unique crystallographic orientation domain with high angle grain boundaries. Therefore, the image quality map exhibits that ferrite grains have a very small crystallographic grain size. According to crystallographic grain size distribution as shown in Fig. 7(c), The main area fraction of the grain size (diameter) ranges from 2 to $6 \mu \mathrm{m}$ and the mean effective grain size of the FGHAZ is $5.3 \mu \mathrm{m}$, which is much smaller than that of the FLZ $(15.7 \mu \mathrm{m})$. These high density of effective grain boundaries can act as obstacles to cleavage propagation, forcing the cleavage crack to change the microscopic plane of propagation frequently. Therefore, the fracture mophology of FGHAZ has small unit cleavage facet and the crack propagation energy improves to $83.9 \mathrm{~J}$, as shown in Table 2. Compared with crystallographic features of FLZ and FGHAZ, it can be concluded that refinement the crystallographic grains is an effective method to improve the toughness of welded joint, especially for CGHAZ. Commonly, there are two main methods proposed to refine crystallographic grain size of HAZ microstructure. One is the addition of special alloying elements to form high melting point oxide inclusion to inhibit austenite grain coasening and to promote the formation of the acicular ferrite. The other is post weld heating treatment to reaustenitizing microstructure. However, although these two methods have been developed for a long time and made great progress, some problems still exist in practice of these methods, such as the heating treatment can not eliminate the detrimental crystallographic features because coarse crystallographic grain size was reproduced on cooling suggested by Yan et al. ${ }^{[21]}$. Therefore, the refinement mechanism of the crystallographic grains during welding should be further studied in detail to improve the impact toughness.

\section{Conclusions}

(1) After the base plate was subjected to multipass submerged arc welding process, the CGHAZ has coarse granular bainite with quite a number of large $\mathrm{M}-\mathrm{A}$ constituents, while microstructure in the FGHAZ consists of fine polygonal ferrite and acicular ferrite. Both crack initiation and propagation energies of the FLZ specimens deteriorate seriously compared with the toughness of the FGHAZ specimens according to the impact results.

(2) The lower crack initiation energy in the FLZ specimens mainly attributes to the coarse inclusions 
in WM matrix and coarse M-A constituents in the CGHAZ. The coarse crystallographic grains in the CGHAZ lead to a large cleavage facet and decrease the crack propagation energy.

(3) The FGHAZ has fine effective grains and high density of high misorientation grain boundary, which play vital role in both inhibiting the crack propagation and improving the toughness. Therefore, refinement of the crystallographic grains is an effective method to improve the HAZ toughness.

\section{Acknowledgements}

This work was supported by the National Natural Science Foundation of China (No. 51074052) and the Fundamental Research Funds for the Central Universities (No. N100607001).

\section{REFERENCES}

[1] B. de Meester, ISIJ Int. 37 (1997) 537.

[2] F. Matsuda, K. Ikeuchi, J. Liao and H. Tanabe, Trans. JWRI 23 (1994) 49.

[3] L.D. Yao, X.T. Zhao and S.X. Zhao, U. S. Patent 0032062A1 Feb 11 (2010).

[4] M. Shome, Mater. Sci. Eng. A 445-446 (2007) 454.

[5] N.J. Smith, J.T. Mcgrath, J.A. Gianetto and R.F. Orr, Weld Res. 68 (1989) 112.

[6] F. Matsuda, K. Ikeuchi, H. Okada, I. Hrivnak and H. S. Park, Trans. JWRI 23 (1994) 231.
[7] S. Talas, Mater. Des. 31 (2010) 2649.

[8] R. Petrov, O.G. Leon, J.J.L. Mulders, A.C.C. Reis, J. H. Bae, L. Kestens and Y. Houbaert, Mater. Sci. Forum 550 (2007) 625.

[9] A.F. Gourgues, H.M. Flower and T.C. Lindley, Mater. Sci. Technol. 16 (2000) 26.

[10] M. Diaz-Fuentes, A. Iza-Mendia and I. Gutierrez, Met. Mater. Trans. A 34 (2003) 2505.

[11] A.M. Guo, R.D.K. Misra, J.B. Liu, L.Chen, X.L. He and S.J. Jansto, Mater. Sci. Eng. A 527 (2010) 6440.

[12] J.M. Roudriquez-Ibabe, Mater. Sci. Forum 284-286 (1998) 51.

[13] ISO 9016, Destructive Tests on Welds in Metallic Materials-impact Tests-test Specimen Location, Notch Orientation and Examination, IDT (2001).

[14] C.L. Davis and J.E. King, Metall. Mater. Trans. A 25 (1994) 563.

[15] L.Y. Lan, C.L. Qiu, D.W. Zhao, X.H. Gao, and L.X. Du, Mater. Sci. Eng. A 529 (2011) 192.

[16] Y. Ohmori, H. Ohtani and T. Kunitake, Met. Sci. 8 (1974) 357

[17] A. Lambert-Perlade, A.F. Gourgues, J. Besson, T. Sturel and A. Pineau, Metall. Mater. Trans. A 35 (2004) 1039.

[18] W. Wang, W. Yan, L. Zhu, P. Hu, Y.Y. Shan and K. Yang, Mater. Des. 30 (2009) 3436.

[19] Y.M. Huang, Y.M. Wu and C.X. Pan, Mater. Sci. Technol. 6 (2010) 750.

[20] V.M. Goritskii and D.P. Khromov, Strength Mater. 16 (1984) 867.

[21] P. Yan, O.E. Gungor, P. Thibaux and H.K.D.H. Bhadeshia, Sci. Technol. Weld. Join. 15 (2010) 137. 